Published in final edited form as:

Technol Innov. 2012 ; 14(1): 1-2. doi:10.3727/194982412X13378627621554.

\title{
TECHNOLOGY AND INVENTION
}

\author{
Paul R. Sanberg* and Howard J. Federoff ${ }^{\dagger}$ \\ *Office of Research \& Innovation, University of South Florida, Tampa, FL, USA \\ †Medical Center, Georgetown University, Washington, DC, USA
}

This issue of Technology and Innovation-Proceedings of the National Academy of Inventors ${ }^{\circledR}$ brings together five articles on technology and invention produced by scholars from different disciplines. Except for the first article by Gongola from the USPTO, most of the articles were written in collaboration with scholars from the University of South Florida, one of the Charter Member Institutions of the National Academy of Inventors ${ }^{\circledR}$ (NAI). Future issues will feature articles from inventors and faculty members from the other 33 Charter Member Institutions of the NAI as well as other national and international universities.

The articles describe different aspects of invention and human interaction with technologies, high-lighting the complexity behind any attempt to translate scientific discoveries to the improvement of everyday life. This issue also includes the abstracts of the oral and poster presentations of the Inaugural Conference of the National Academy of Inventors ${ }^{\circledR}$.

The issue begins with the discussion of a topic of great interest to American inventors: the implementation of the America Invents Act. Gongola's article presents the main transformations this Act will produce in the patenting process, most of which are geared towards modernizing US patent law. The author indicates that this will be a gradual process that will depend on the active participation of individual inventors, small businesses, universities, and corporations. The United States Patent and Trademark Office (USPTO) hopes to maintain open communication channels in order to receive feedback from the public.

The next article sheds light on the negative consequences of certain inventions. Martin and Martin draw our attention to the dangers of Bisphenol A, a component of plastics. Their article points to the fact that valuable inventions such as thermoplastics not only change the way we live, but also create problems of their own that we need to be prepared to deal with in the long run.

Pfister and Teramoto Kimura discuss the unintended consequences of inventions when they present the case of a computer program designed to teach hearing students Mexican Sign Language, which ultimately resulted in an excellent tool for teaching sign language to deaf

Copyright $\odot 2012$ Cognizant Comm. Corp.

Address correspondence to Paul R. Sanberg, Office of Research \& Innovation, University of South Florida, 3702 Spectrum Boulevard, Suite 175, Tampa, FL 33612-9444, USA. Tel: 813-974-3348; psanberg@ research.usf.edu. 
students as well. The authors indicate that "the creation of this computer program, a unique didactic tool that addressed a community need, surprised the inventor and participants when unintentional learning objectives for deaf and hearing children were subsequently revealed." Their article points to the new paths technological innovation can take when inventions are appropriated by new, and often untargeted, populations.

The article by Vindrola-Padros and Whiteford touches on a slightly different aspect of the human use of technology. The authors are mainly concerned with the issue of access to medical technologies for the treatment of pediatric cancer. They document the experiences of families who decide to migrate to a neighboring country to find treatment for the child because of the inability to secure these services in their country of origin. The article makes us think about the fact that even though great advances have been made in medical care, much works needs to be done in guaranteeing timely and equal access to these technologies.

In their article, Giunta and colleagues use a review and their own research to demonstrate that smoking is a risk for Alzheimer's disease (AD). The authors show that the evidence provided by new, larger, studies has contributed to the questioning of previously held notions that smoking was somehow protective, or did not induce, AD. Their article also calls for future studies that can clarify the specific cellular mechanisms through which smoking promotes AD.

Finally, the issue includes the abstracts from the Inaugural Conference of the National Academy of Inventors ${ }^{\circledR}$, which was hosted by the University of South Florida on February 16-17, 2012. This conference brought together researchers from multiple national and international academic institutions to discuss issues pertaining to translational technology and science. It sought to create an environment of interdisciplinary collaboration and promote innovation and entrepreneurship.

The first keynote address was given by David Kappos, Under Secretary of Commerce for Intellectual Property and Director of the United States Patent and Trademark Office, where he discussed the trajectory of the USPTO since his appointment in 2009. The second keynote speaker was Dr. Thomas J. Fogarty, inventor of the cardiac balloon catheter. His presentation focused mainly on institutional barriers to innovation. The conference also included oral presentations led by 24 speakers from the National Academy of Inventors' Charter Member Institutions, which focused on a wide range of topics such as the relationship between universities and industries, the importance of supporting faculty entrepreneurship, and the need to implement strategic planning within technology transfer offices. The abstracts of these presentations, as well as those of the 75 posters presented at the conference, are included in this issue.

We would like to take this opportunity to thank all of the peer reviewers who participated in the evaluation of the articles that were published in Technology and Innovation's four issues of 2011. We hope you will continue to review manuscripts for the journal in the future. 